\title{
INHIBITION OF APATITE DISSOLUTION DUE TO FORMATION OF CALCIUM OXALATE COATING
}

\author{
MASAMI NANZYO, YASUO NAKAMARU and SHIN-ICHI YAMASAKI \\ Division of Agriculture, Graduate School of Tohoku University, Sendai, 981-8555, Japan
}

\begin{abstract}
The amount of apatite dissolution increased with decreasing final $\mathrm{pH}$ when two apatite samples $(0.2-0.04 \mathrm{~mm})$ were treated with $10 \mathrm{mmol} \mathrm{L}^{-1}$ of citric acid or 4-0 mmol L-1 $\mathrm{HCl}$. However, when they were treated with $10 \mathrm{mmol} \mathrm{L}^{-1}$ of oxalic acid, the amount of dissolution was much smaller than the treatment with the same concentration of citric acid at around $\mathrm{pH}$ 4. According to the X-ray diffraction (XRD), scanning electron microscope (SEM) observation and energy dispersive X-ray analysis (EDX) of the oxalic acid-treated apatite, a coating of calcium oxalate was formed on the surface of the apatite particles which inhibited the dissolution of apatite under the experimental conditions.
\end{abstract}

\section{INTRODUCTION}

One of the research goals for the direct application of phosphate rocks to agricultural lands is to find an effective combination of soil, climate, crop and management1). Among the soil factors, soil $\mathrm{pH}$ primarily affects the dissolution of apatite1). With a decrease in soil $\mathrm{pH}$, the amount of apatite dissolution increases 1 ).

In the weakly acidic to neutral soil $\mathrm{pH}$ range, the solubility of apatite is not very high and the effect of organic acids having a chelating ability may be an important plant factor1). It is well-known that some crops exudate chelating organic acids from their roots. For example, citric and malic acids are exudated by chick pea (Cicer arietinum L.) ${ }^{2,3)}$ and P-deficient rape plants (Brassica napus L.) $\left.{ }^{1}\right)$ and piscidic acid by pigeon pea (Cajanus cajan Millsp.). Oxalic acid was found in soil solutions of forest and cultivated soils at a concentration of $60-1043 \mu$ mol L-1 4,5,6).

Fresh rhyoritic to andesitic volcanic ash commonly include 1 - 3 g P2O5 $\mathrm{kg}^{-1}$ of apatite ${ }^{7,8}$ ) and this may be useful as a phosphorus $(\mathrm{P})$ source for revegetation and restoration of agriculture especially in the area where soluble P fertilizers are not easily available. Hence, we examined the reactions of various soil components and apatite contained in fresh Mt. Pinatubo volcanic ash, Philippines, to seek an effective soil management method to utilize the apatite for crop production.

Received January 18, 1999; approved April 21, 1999 
During this study, we found that the dissolution of $\mathrm{P}$ with oxalic acid treatment showed a different $\mathrm{pH}$ dependence from that with dilute $\mathrm{HCl}$ or citric acid treatment. The amount of $\mathrm{P}$ dissolved with the oxalic acid treatment remained small even at a $\mathrm{pH}$ of $3-4$ while it increased with decreasing $\mathrm{pH}$ during the treatment with the other materials. As it was impossible to isolate apatite particles from the volcanic ash, the reason for the low $\mathrm{P}$ dissolution by oxalic acid treatment was not elucidated. The objective of the present study was to confirm the mechanism of $\mathrm{P}$ dissolution inhibition by the oxalic acid treatment using high purity apatite particles.

\section{EXPERIMENTAL}

Two particulate apatite samples from Florida, U.S.A. (Florida apatite)9) and Makatea Island, France (Makatea apatite) ${ }^{10)}$ were used. The analytical P, Ca and F11) contents were 141, 373 and 33 $\mathrm{g} \mathrm{kg}^{-1}$ for the Florida apatite and 161, 406 and $28 \mathrm{~g} \mathrm{~kg}^{-1}$ for the Makatea apatite on an air-dried basis, respectively. Because $\mathrm{F}$ content of these apatite samples were intermediate between those of fluorapatite and hydroxyapatite, solubility isotherms of these samples seem to lie between the two pure minerals12). The major mineral of these samples was confirmed to be apatite by XRD. Florida apatite contained a small amount of quartz, which is not likely to affect solubility of the apatite due to its scattered occurrence in the apatite particle as small discrete mineral grains. A particle-size fraction of $0.2-0.04 \mathrm{~mm}$, which was used for the dilute $\mathrm{HCl}$, oxalic acid and citric acid treatments, was prepared using sieves.

To $20 \mathrm{mg}$ of the apatite samples, $100 \mathrm{~mL}$ of various acid solutions was added. The acid solutions were $10 \mathrm{mmol} \mathrm{L-1}$ oxalic acid aqueous solution adjusted to $\mathrm{pH} \mathrm{3.0,4.0,5.0} \mathrm{or} 6.0$ using $\mathrm{NaOH}, 10$ mmol L-1 citric acid aqueous solution adjusted to $\mathrm{pH} 3.0,4.0,5.1$ or 6.1 using $\mathrm{NaOH}$ and

4, 2, 1, 0.5, 0.2 and $0 \mathrm{mmol} \mathrm{L}-1$ of $\mathrm{HCl}$. The mixtures were shaken for $16 \mathrm{~h}$ at $25^{\circ} \mathrm{C}$. After measuring the final $\mathrm{pH}$, the supernatant solutions were separated from the apatite particles by centrifugation and filtration. $\mathrm{P}$ and $\mathrm{Ca}$ in the supernatant solutions were determined by the molybdenum blue colorimetric method13) and atomic absorption method, respectively. The treated apatite particles were used for XRD after washing with distilled water, air-drying, and grinding.

To about $10 \mathrm{mg}$ of Florida apatite particles having a diameter near $1 \mathrm{~mm}, 25 \mathrm{~mL}$ of $10 \mathrm{mmol} \mathrm{L}-1$ oxalic acid solution adjusted to $\mathrm{pH} 4$ by $\mathrm{NaOH}$ was added and shaken for $16 \mathrm{~h}$ at $25^{\circ} \mathrm{C}$. After separation of the apatite particles, washing with distilled water and air-drying, an apatite particle was cut with scissors under an optical microscope to conduct EDX elemental analysis of the surface and section of the oxalic acid-treated apatite particle. The sample particles were held by double-sided 
adhesive tape on a carbon sample holder and were coated with vacuum-evaporated carbon. The SEM observations were conducted using a HITACHI S4200 operated at $15 \mathrm{kV}$. The EDX analysis was carried out using a Kevex X-ray microprobe equipped with the SEM.

\section{RESULTS AND DISCUSSION}

The dissolution of two apatite samples was dependent on the final $\mathrm{pH}$ when they were treated with $10 \mathrm{mmol} \mathrm{L-1}$ of citric acid or dilute $\mathrm{HCl}$ (FIGURE 1). The amount of $\mathrm{P}$ dissolved from the two apatite samples increased with decreasing final $\mathrm{pH}$ values and was larger after the citric acid treatment than after the dilute $\mathrm{HCl}$ treatment especially in the $\mathrm{pH}$ range between 5 and 6 . This is possibly due to chelation of $\mathrm{Ca}$ and donation of $\mathrm{H}+$ by the citric acid.

In contrast, when the two apatite samples were treated with $10 \mathrm{mmol} \mathrm{L}^{-1}$ oxalic acid, the amount of dissolved $\mathrm{P}$ was much smaller than those treated with citric acid or $\mathrm{HCl}$ in the final $\mathrm{pH}$ ranging between 3.4 and 4.3 (FIGURE 1). When the final $\mathrm{pH}$ was about 3 due to the treatment with citric acid or dilute $\mathrm{HCl}$, the amount of $\mathrm{P}$ dissolved was more than $96 \%$ of the original $\mathrm{P}$ content of the samples. When the final $\mathrm{pH}$ was 3.4 due to the treatment with oxalic acid, the amount of $\mathrm{P}$ dissolved was only about $10 \%$ of the original $\mathrm{P}$ content and was not much different from those at the final $\mathrm{pH}$ of 5 to 7 . The low $\mathrm{P}$ dissolution with oxalic acid treatment compared with citric acid and $\mathrm{HCl}$ treatment was close to the result using the Pinatubo volcanic ash.

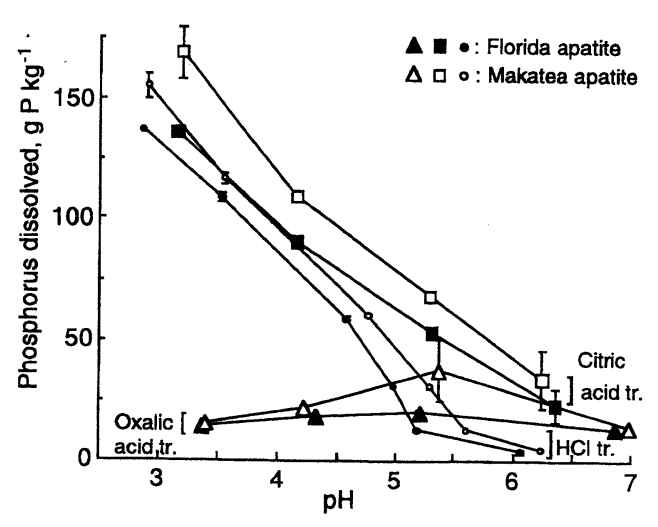

FIGURE 1 Relationship between final $\mathrm{pH}$ and the amount of $\mathrm{P}$ dissolved from Florida and Makatea apatites with $10 \mathrm{mmol} \mathrm{L}^{-1}$ oxalic acid, 10 mmol L-1 citric acid, or 4-0 mmol L-1 $\mathrm{HCl}$ treatment. Vertical bars indicate standard deviation.

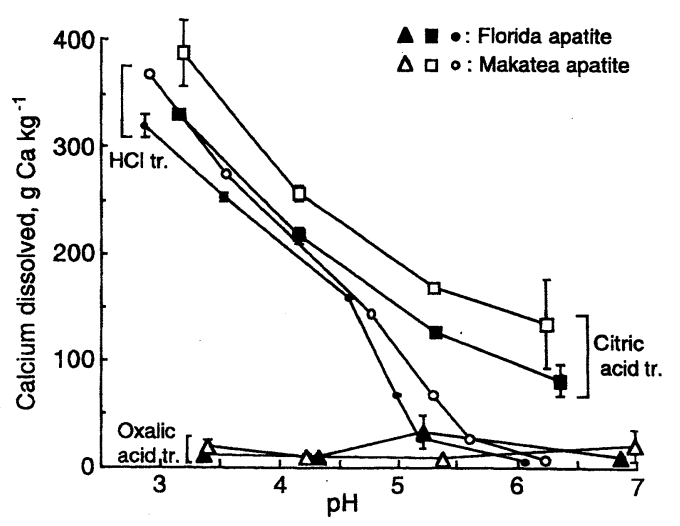

FIGURE 2 Relationship between fianl $\mathrm{pH}$ and the amount of $\mathrm{Ca}$ dissolved from Florida and Makatea apatites with $10 \mathrm{mmol} \mathrm{L}^{-1}$ oxalic acid, $10 \mathrm{mmol} \mathrm{L}^{-1}$ citric acid, or 4-0 mmol L-1 $\mathrm{HCl}$ treatment. Vertical bars indicate standard deviation. 


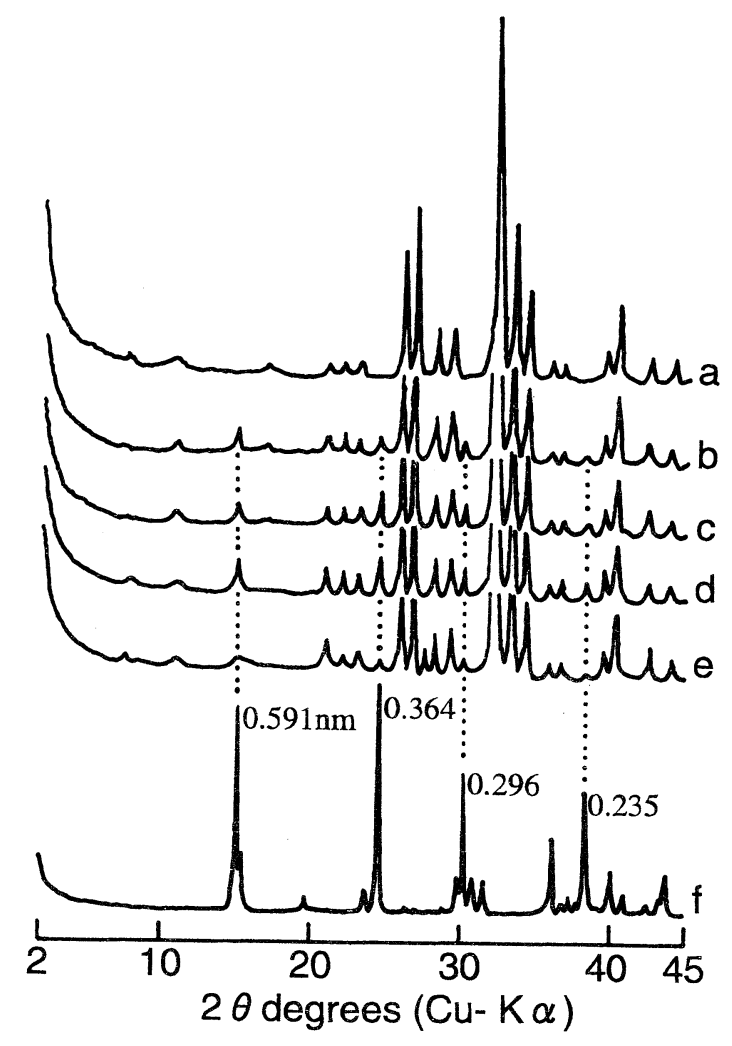

FIGURE 3 X-ray diffraction patterns of untreated Florida apatite (a), Florida apatite treated with 10 mmol L-1 oxalic acid (b: final $\mathrm{pH}=3.4$, $\mathrm{c}$ : final $\mathrm{pH}=4.3$, d: final $\mathrm{pH}=5.2$, e: final $\mathrm{pH}=6.9$ ), and guaranteed grade $\mathrm{CaC} 2 \mathrm{O} 4 \cdot \mathrm{H} 2 \mathrm{O}$ (f).

A similar inhibiting effect by oxalic acid treatment was also observed upon Ca dissolution from the two apatite samples (FIGURE 2). The amount of Ca dissolved increased with decreasing final $\mathrm{pH}$ values when the apatite samples were treated with citric acid or dilute $\mathrm{HCl}$. A higher $\mathrm{Ca}$ dissolution due to citric acid treatment than dilute $\mathrm{HCl}$ treatment was also observed in the final $\mathrm{pH}$ ranging from 5.6 to 6.1 , possibly due to chelating or the $\mathrm{H}^{+}$donating effect of citric acid. However, the amount of Ca dissolved by oxalic acid treatment was remained low and less than $4.2 \%$ of the original content of the apatite samples in the final $\mathrm{pH}$ range between 3.4 and 7 . The dissolution of $\mathrm{Ca}$ was lower than that of $\mathrm{P}$ if one assumes congruent dissolution of an ideal apatite that has an atomic $\mathrm{Ca} / \mathrm{P}$ ratio of 1.67 . This consideration suggests that the net exchange of $\mathrm{P}$ with oxalic acid took place in the solid phase.

The formation of calcium oxalate from the oxalic acid treatment of the Florida apatite was 

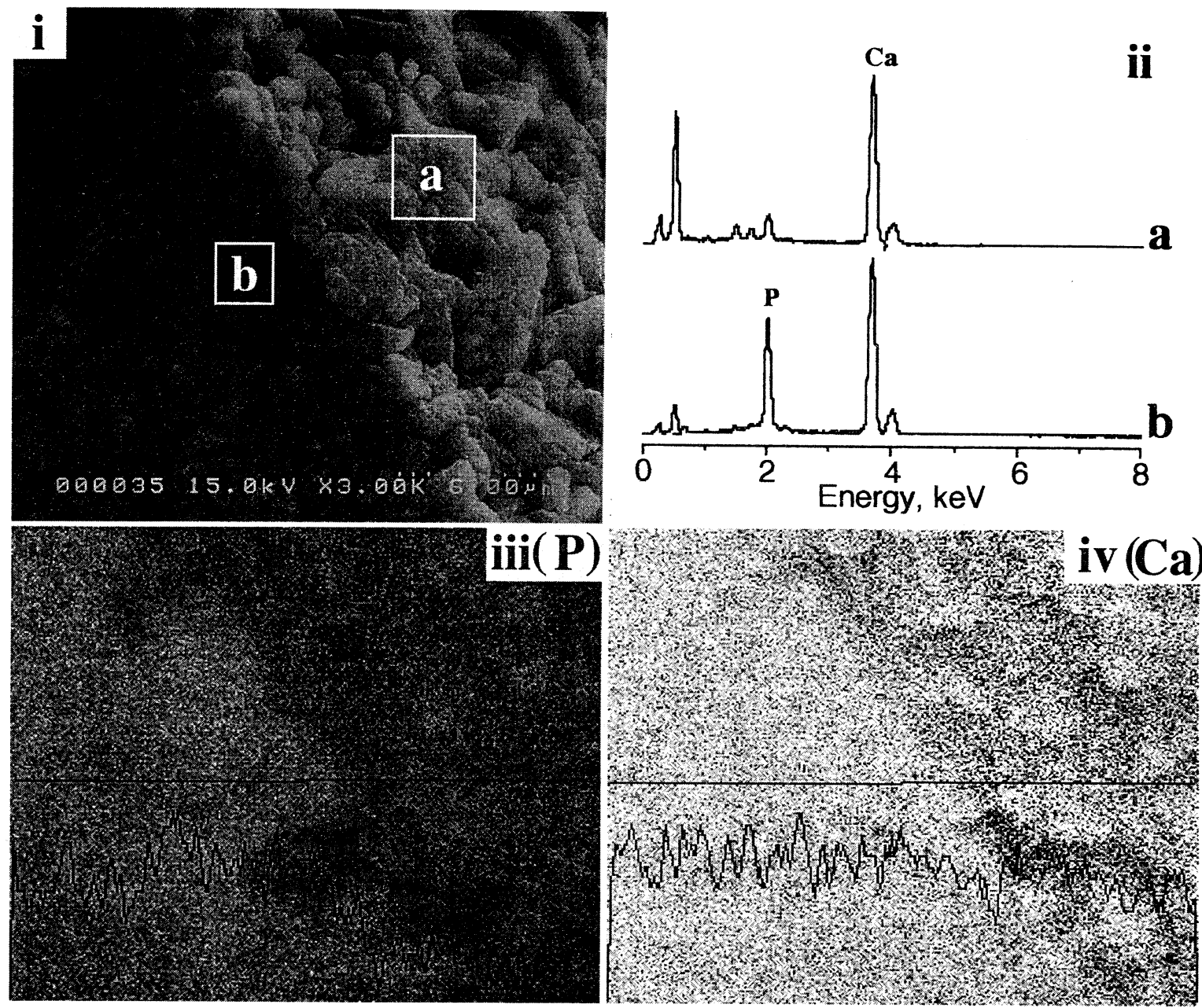

FIGURE 4 SEM image (i), EDX spectra of selected areas (ii), and X-ray element maps of P(iii) and Ca (iv) of the oxalic acid-treated $\left(10 \mathrm{mmol} \mathrm{L}^{-1}\right)$ Florida apatite. Spectra $a$ and $b$ in (ii) were obtained from the analysis of selected square areas a (surface) and b (section) in (i), respectively. Line graphs in (iii) and (iv) show the abundance of $\mathrm{P}$ and $\mathrm{Ca}$ along the horizontal straight lines, respectively

revealed by XRD (FIGURE 3). Similar results were also obtained for the Makatea apatite. Four small diffraction peaks at $0.591,0.364,0.296$ and $0.235 \mathrm{~nm}$ appeared in the XRD patterns of the Florida apatite after oxalic acid treatment in the final $\mathrm{pH}$ range between 3.4 and 7 . These four XRD peaks are identical to the four strongest powder XRD peaks for $\mathrm{CaC}_{2} \mathrm{O}_{4} \cdot \mathrm{H}_{2} \mathrm{O}$. The solubility of calcium oxalate is very low except under strongly acidic conditions. This result indicate that the calcium oxalate formed due to the reaction of oxalic acid and apatite.

The distribution of calcium oxalate after the oxalic acid treatment of the apatite samples was 
elucidated by an SEM-EDX analysis. FIGURE 4-i shows an SEM image of the surface (right-hand side) and the section (left-hand side) of an oxalic acid-treated Florida apatite particle at $\mathrm{pH} 4$.

According to the selected area analysis, the peak intensity for $\mathrm{P}-\mathrm{K} \alpha$ on the surface of the particle was much weaker than that of the section (FIGURE 4-ii ). The element maps and traces of electron microprobe line scans for P (FIGURE 4-iii) and Ca (FIGURE 4-iv) further illustrates the difference in the $\mathrm{P}$ and $\mathrm{Ca}$ distributions between the surface and the section. The abundance of $\mathrm{P}$ is high and almost constant inside the particle and it gradually decreases toward the surface due to formation of the calcium oxalate coating (FIGURE 4-iii). The thickness of the calcium oxalate coating was estimated to be less than $2 \mu \mathrm{m}$ based on the results from the line scan for P. A similar result was also observed in the line scan for Ca (FIGURE 4-iv) although the difference in Ca content was small between the surface and the section. Thus, it was confirmed that calcium oxalate was formed by oxalic acid treatment of the apatites as a surface coating material and the calcium oxalate coating inhibited further dissolution of apatite.

According to the results obtained here, the existence of oxalic acid in soil may not be necessarily profitable for utilization of apatite although oxalic acid is effective for avoiding $\mathrm{Al}$ toxicity in acid soils6). When powdery apatite of less than $0.04 \mathrm{~mm}$ was used, however, the inhibitory effect on the apatite dissolution was smaller than that for the apatite having a particle size of 0.2-0.04 mm. Thus, the extent of the inhibitory effect of the calcium oxalate coating was dependent on the particle size of the apatites used in this experiment.

Acknowledgment: The authors thank Dr. T. Higuchi of the National Institute of Agro-Environmental Sciences for providing the apatite samples. They also thank Mr. T. Sato, Faculty of Agriculture, Tohoku University, for operating the scanning electron microscope and assisting in the EDX analysis.

\section{REFERENCES}

1. S.S.S. Rajan, J.H.Watkinson and A.G. Sinclair, Adv. Agron. 57, 77 (1996)

2. Y. Ohwaki, Jap. J. Soil Sci. Plant Nutr. 69, 239 (1998)

3. N. Ae, Jap. J. Soil Sci. Plant Nutr. 69, 227 (1998)

4. R.D. Harter and N. Naidu, Adv. Agron. 55, 219 (1995)

5. T.R. Fox and N.B. Comerford, Soil Sci. Soc. Am. J., 54, 1139 (1990)

6. N.V. Hue, G.R. Craddock and F. Adams, Soil Sci. Soc. Am. J., 50, 28 (1986)

7. M. Nanzyo, T. Takahashi, A. Sato, S. Shoji and I. Yamada, Soil Sci. Plant Nutr., 43, 839 (1997)

8. M. Nanzyo and S.-I. Yamasaki, Phos. Res. Bull., 8, 95 (1998)

9. T. Kanazawa (ed), Inorganic Phosphorus Chemistry (Kodansha, Tokyo, 1985) p.11.

10. T. Kanazawa, J. Sci. Soil Manure, Japan, 31, 181 (1960)

11. G.H. McClellan and J.R. Lehr, Amer. Mineral., 54, 1374 (1969)

12. F.E. Khasawneh and E.C. Doll, Adv. Agron., 30, 159 (1978)

13. J. Murphy and J.P. Riley, Anal. Chim. Acta, 27, 31 (1962) 